\title{
Active Connections: Means For Faculty To Create An Environment In Which Students WANT To Engage!
}

\author{
Don Forrer, Hodges University, USA \\ Stephanie Bechtel, Central Michigan University, USA \\ Kendra Brown, Central Michigan University, USA \\ Jose Mabesa Jr., Central Michigan University, USA \\ Linda Gunn, Western Governors University, USA \\ Richard L. Hayes, Central Michigan University, USA \\ Lisa Fall, Central Michigan University, USA \\ Todd Wilmore, Central Michigan University, USA
}

\begin{abstract}
This interactive, cross-disciplinary research explores face-to-face and online strategies for faculty to deploy in the classroom that encourage connections beyond forced engagement methodologies commonly used. Concentration is on methods of connecting that are "out of the mainstream" and benefit both students and faculty. Findings indicate that the more students feel as a valued participant of the learning community, the more they engage in the class activities.
\end{abstract}

Keywords: Connection; Student Engagement; Learning Community

\section{INTRODUCTION}

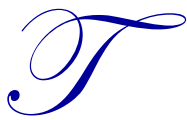

his research explores options for faculty to deploy in the classroom (traditional, online, and nontraditional) to encourage connections beyond the typical methodologies commonly used. This paper is also designed to demonstrate methods instructors can use to encourage connections between faculty/student and student/student. There is little doubt that teaching has changed tremendously during the second decade of the $21^{\text {st }}$ century. Academia's acceptance of distance education fueled by new technology that allows an online class to be as effective and interactive as a traditional classroom experience. Most universities are migrating to standardized templates and course materials. As a result, professors can, if they desire, teach a class using the provided information, thereby minimizing interaction with students. This is especially true in an online environment. However, a professor can create a thriving learning community by expanding the arena of knowledge to entice students to connect and engage with the course materials in exciting ways.

Additionally, recruitment and retention is increasingly competitive and dependent heavily on a student's ability to participate and interact in the classroom. Encouraging connections in the learning environment plays a key role to students' positive perceptions and ability to learn. Students are seeking maximum value for education dollars and expect a quality education. Unfortunately, many classroom professors rely on standard methods of forcing interaction through assignments such as a group projects, discussion boards, or open-ended questions. While there is a place for all of the listed activities, more is required for a strong learning environment. Future classrooms require innovation from the faculty member to inspire a learning community among course participants. The key is to create interaction driven by students. Students see the value and want to connect when they are inspired.

In today's academic environment, students have choices. The traditional faculty member with a white note pad rimmed with the yellow of age coupled with lectures from years of experience is generally not capturing students' imagination and creating enthusiasm. A faculty member using traditional lectures, open discussion, assignments, 
examinations, and a research paper are finding it hard to stimulate students' intellectual curiosities. Connections are imperative to create an environment where students want to engage. This research explores methodologies utilized by successful faculty in this emerging territory.

Research indicates that academia as an industry is declining in enrollments. Table 1 demonstrates changes in student enrollments from 2012 to 2015 . This trend will probably continue due to demographic pressure.

Table 1. Enrollment change from the previous year (percentage)

\begin{tabular}{l|c|c|c|c|c|c|c|}
\hline & Fall 2012 & Spring 2013 & Fall 2013 & Spring 2014 & Fall 2014 & Spring 2015 & Fall 2015 \\
\hline All & $-1.8 \%$ & $-2.3 \%$ & $-1.5 \%$ & $-0.8 \%$ & $-1.3 \%$ & $-1.9 \%$ & $-1.7 \%$ \\
\hline 4 Year Public & $-0.2 \%$ & $-0.8 \%$ & $0.4 \%$ & $0.8 \%$ & $0.7 \%$ & $0.1 \%$ & $0.4 \%$ \\
\hline 4 Year Private Nonprofit & 0.5 & $0.5 \%$ & $1.3 \%$ & $2.0 \%$ & $1.6 \%$ & $-0.2 \%$ & $-0.3 \%$ \\
\hline 4 Year For-Profit & $-7.2 \%$ & $-8.7 \%$ & $-8.7 \%$ & $-4.9 \%$ & $-0.4 \%$ & $-4.9 \%$ & $-13.7 \%$ \\
\hline 2 Year Public & -3.5 & $-4.1 \%$ & $-3.3 \%$ & $-2.9 \%$ & $-4.4 \%$ & $-3.9 \%$ & $-2.4 \%$ \\
\hline
\end{tabular}

Retrieved from 2014/2015 Undergraduate degree earners report (2016).

National Student Clearinghouse Report. https://nscresearchcenter.org/wp-content/uploads/2014-15UndergradDegreeEarnersRpt.pdf

According to the Undergraduate degree earners report (2016), there is a slight decrease in first time college students over a three year period. A significant decline was noted for adult students returning to earn their degree were significantly declining. These trends will continue unless the economy changes to increase the demands for a degree.

Table 2. Enrollment by age group

\begin{tabular}{|c|c|c|c|c|c|c|c|}
\hline & \multirow[b]{2}{*}{ Age } & \multicolumn{2}{|c|}{ Fall 2013} & \multicolumn{2}{|c|}{ Fall 2014} & \multicolumn{2}{|c|}{ Fall 2015} \\
\hline & & Enrollment & \% Change & Enrollment & \% Change & Enrollment & \% Change \\
\hline \multirow{2}{*}{ All } & $24 \&$ Under & $12,483,914$ & $-0.4 \%$ & $12,425,257$ & $-0.5 \%$ & 12,393792 & $-0.3 \%$ \\
\hline & Over 24 & $7,401,289$ & $-3.4 \%$ & $7,194,616$ & $-2.8 \%$ & $6,886,680$ & $-4.3 \%$ \\
\hline \multirow{2}{*}{4 Year Public } & $24 \&$ Under & $5,623,696$ & $1.5 \%$ & $5,712,772$ & $1.6 \%$ & $5,761,947$ & $0.9 \%$ \\
\hline & Over 24 & $2,340,394$ & $-2.1 \%$ & $2,307,672$ & $-1.4 \%$ & $2,293,672$ & $-0.6 \%$ \\
\hline \multirow{2}{*}{$\begin{array}{l}4 \text { Year Private } \\
\text { Nonprofit }\end{array}$} & $24 \&$ Under & $2,312,383$ & $0.7 \%$ & $2,349,735$ & $1.6 \%$ & $2,346,861$ & $-0.1 \%$ \\
\hline & Over 24 & $1,449,570$ & $2.3 \%$ & $1,473,730$ & $1.7 \%$ & $1,464,314$ & $-0.6 \%$ \\
\hline \multirow{2}{*}{$\begin{array}{l}4 \text { Year For- } \\
\text { Profit }\end{array}$} & $24 \&$ Under & 246,339 & $-14.7 \%$ & 253,119 & $2.8 \%$ & 221,221 & $-12.6 \%$ \\
\hline & Over 24 & $1,074,768$ & $-8.5 \%$ & $1,062,048$ & $-1.2 \%$ & 913.753 & $-14 \%$ \\
\hline \multirow{2}{*}{2 Year Public } & $24 \&$ Under & $3,878,137$ & $-1.3 \%$ & $3,786,656$ & $-2.4 \%$ & $3,770,297$ & $-0.4 \%$ \\
\hline & Over 24 & $2,451,494$ & $-6.2 \%$ & $2,265,413$ & $-7.6 \%$ & $2,136,121$ & $-5.7 \%$ \\
\hline
\end{tabular}

Retrieved from 2014/2015 Undergraduate degree earners report (2016).

National Student Clearinghouse Report. https://nscresearchcenter.org/wp-content/uploads/2014-15UndergradDegreeEarnersRpt.pdf

Assuming that the market will continue to decline over the near future, universities must adjust their enrollment goals to make the most of a smaller market. This research argues that meaningful programs that cause the student to want to engage is a valuable key to future growth. Students currently want a skill that they can apply immediately in the workplace - which is meaningful to their educational goals. A learning environment created to excite while educating provides incentives for students to select particular programs and schools.

\section{TALKING IS NOT TEACHING - CREATING A LEARNING}

In their book, Brown, Roediger, \& McDaniel (2014), a story is described where a pilot lost oil pressure, thereby leaving him with a series of options in order to save the aircraft and himself. Through a series of mental checklists, coupled with personal experience, the pilot was able to shut down the engine and make it to the nearest airstrip without catastrophic consequences. The lesson of the story was that learning is more than rope memorization and constant examination. While this element of education is, and will remain, important, the authors contend that effortful learning is the best approach. In other words, when learning is desired by the student, the results are better. Therefore, creating a learning environment where students want to connect with the subject matter will positively complement the traditional classroom activities of reading text and taking exams. 
Brown, Roediger, \& McDaniel (2014) indicate that a foundation of knowledge in the subject matter is necessary for successful learning. Their research also recommends that the traditional education principles of memorization, continued learning, and counterintuitive strategies are important to the foundation of learning. However, their research demonstrates that more is necessary for the student to want to engage in the process. In the example of the airplane pilot, the authors described how training included memorization, PowerPoint presentations, exams, reading, and other traditional educational tools. The pilot indicated that it was not until the instructor brought the students to the simulation module that the educational experience came to life and brought meaning to the subject matter. This hands-on training caused the future pilot to want to be connected thus saving him and the aircraft when an emergency occurred.

This illustration of heroism in the two paragraphs begins the research journey to define a learning environment where students want to engage. The simulation exercises brought the hours of reading, lectures, and demonstrations to life as far as the pilot was concerned. Learning environments, when simulation is included, made the student in question want to engage in the process and brought meaning to the traditional classroom activities. The research by Brown, Roediger, \& McDaniel (2014) suggests that if professors want students to willingly engage, the realization that academia is effective in delivery, but not efficient in the art of engaging students. This research explores student engagement through the innovation of creative programs.

Table 3 illustrates some suggestions of methodologies to create a learning environment where students willingly engage. This research is not meant to suggest that there are few programs in academia where students are willingly engaged. In fact, this research suggests the exact opposite and uses examples to illustrate efficient engaging programs. However, many students have experienced the professor with the stack of yellowed notepads still teaching the same material and resistant to change. In today's competitive market the school without creativity and currency in educational endeavors provides an opportunity for the university that is willing to excite and engage students with relevant, current information. Table 3 offers a few examples of traditional versus creative practices.

Table 3. Traditional versus creative methodologies

\begin{tabular}{l|l}
\hline \multicolumn{1}{c}{ Traditional Connection Methodologies } & \multicolumn{1}{c}{ Creating an Engaging Environment } \\
\hline Group Projects & Interactive Group sessions \\
\hline Assignments/ Case Studies & Real World Scenarios \\
\hline Examinations/Quizzes & Gaming Theory \\
\hline Assignments / Activities & Simulation \\
\hline Assignments / Text & Computer Supported Collaborative Learning \\
\hline Guest Speakers & Visits to Corporations/Factories/etc. \\
\hline Discussion Board & Interactive Discussion \\
\hline Lecture Collaborate Session & Interactive Collaborate Sessions \\
\hline Videos & Interactive Videos \\
\hline Open-Ended Questions & Connections (Student to Student) \\
\hline Lectures & Connections (Student to Faculty) \\
\hline Created by Authors. &
\end{tabular}

Based on the information discussed early in the manuscript, it is imperative that institutions examine the traditional role of faculty. Course design and the ability to entice willing student engagement play an important role in recruitment and retention. Potential students are not only researching post-graduate placement results but the skills they will obtain from the program as well. Potential employers are also reviewing university programs for an immediate "fit" in their organizational culture. These activities are not new, but it has taken on increased importance (Sasse, Schwering, \& Dochterman, 2008; Barnett, 1992 p.A40).

Research by Sasse, Schwering, \& Dochterman, (2008) examined the role of faculty by applying the value chain analysis traditionally used to evaluate a company. In a value chain, the researchers analyzed the supporting elements of a company against their relationship to the total success of the product. Their research classified creation of knowledge, application of knowledge, and course curriculum as "upstream activities" in their value chain as depicted in figure 1. The research categorized design, delivery, and student learning as "downstream activities". Conclusions reached revealed professors who spent the majority of their time in the "upstream activities" were a 
result of reduced teaching loads that allowed for research and community efforts. This research also concluded that traditional roles of faculty must be examined to create courses that entice student engagement and utilize the full potential of their esteemed faculty.

Figure 1. Academic Value Chain as depicted in Sasse, C., Schwering, R., \& Dochterman, S. (2008). Rethinking faculty role in a knowledge age. Academy of Educational Leadership Journal. (12)2, 35-49.

Academic Value Chain as depicted in Sasse, C., Schwering, R., \& Dochterman, S. (2008). Rethinking faculty role in a knowledge age. Academy of Educational Leadership Journal. (12)2, 35-49

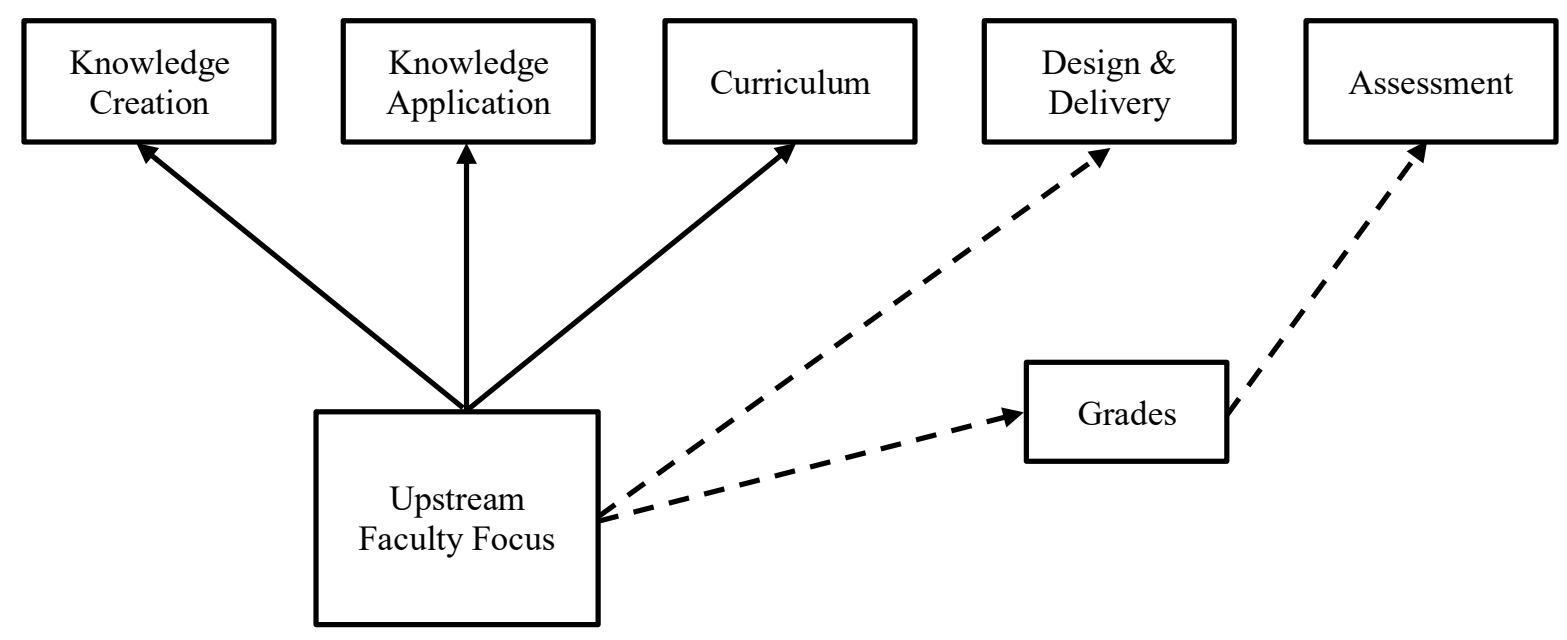

Figure X. Depicted by Sasse, Schwering \& Dochterman, 2008.

To this point, this research has demonstrated that the adult education market in decline and the role of traditional faculty must be examined. This is critical for recruitment and retention efforts must include emphasis on the product delivered. Evaluating and designing the curriculum to provide engagement opportunities that are appealing to students and employers is the key to future success. The remainder of this paper concentrates on Table 3 and the learning tools that will encourage students to want to engage.

The main goal of educational institutions is to provide students with the skills to be successful in their future employment (Meyer \& McNeal, 2011). A variety of methodologies are employed to reach this goal. Research indicates that many institutions rely on collaboration in either online or group activities for a traditional classroom (Chiong \& Jovanovic, 2012; Meister \& Willyerd, 2010). In order to interact with students in a manner that causes them to want to engage, it is not enough to merely offer group projects. Group work must be meaningful, valueadded, and interactive. Interactive group projects are designed to enhance the classroom with real-world scenarios that examine best practices in the workplace in a manner in which students are excited about the results.

Generally, small interactive groups are recognized as being the most effective (Chiong \& Jovanovic, 2012; Finegold \& Cooke, 2006). Small groups are easier to control and students work better when everyone can be involved. Utilizing small groups keep students engaged and help students get the most from the learning experience. The design of the group project must include leadership, designed control, flexibility, scheduling, and a complete 
understanding of the grading process set against real-world challenges. Otherwise, students are reluctant to participate.

One of the best examples of an interactive group project and utilizing real-world scenarios to entice student to want to get involved is the \$3.5 million Roland George Investments Program at Stetson University. This interactive program began in 2001 with a modest endowment and achieved success through student management. The two semester program requires students to participants in an investment firm responsible for portfolio management. Students enroll in the program because they want to participate in a real-world experience. Furthermore, the program has achieved tremendous success in placing graduates in the field of finance (Roland George Investment Program, 2017). This university created a learning environment where students want to engage.

Traditional education uses examinations and quizzes for assessment purposes and this will always be valuable to the education process. However, replacing examinations with gaming theory will enhance the value of the subject matter and achieve an acceptable assessment methodology. In gaming theory, students interact with classmates to learn course material through practical application in the form of a game. While there are some materials available through publishers and commercial sources, this method usually requires creativity by the professor to develop meaningful games. Gaming theory requires leadership and leader involvement. A well-designed game will provide peer interaction, critical thinking, feedback, and opportunity. Student engagement promoted through gaming theory results in a method that is rewarding while replicating a real-world issue (Ellis, 2001; Gabriel, 2004).

An example of gaming theory was provided by Wilmore (2014) by using the Winston Churchill's secret intelligence group at Bletchley Park during World War II. Wilmore's research utilized Gaming Theory to create secret code and clues to determine motivation theory. Students work through a series of game moves to build the various theories around motivation and then apply the results to a real-world scenario. According to Wilmore, students will readily engage if they are simulated in a manner in which the learning is meaningful.

Simulation is a tool that has been in use for many years. The US Military and the health care field have made extensive use of simulations to reproduce a real-world scenario. Simulation is a cost reduction measure; it is efficient in replicating vital functions in a safe environment. Research indicates that students willingly engage if they are involved in a learning experience that simulates the task they will be expected to accomplish in the workplace. The more involved the student is in the learning experience, the better the lesson retention. A positive learning environment is fostered through simulation if there is adequate institutional support and the instructor is well prepared (Klassen \& Willoughby, 2003).

Examples abound in successful simulation activities. Several simulation products in strategy and marketing are utilized in business schools. The research by Klassen and Willoughby (2003) utilized a simulation of a sporting goods store and management of inventory. This game utilized a fabricated company with data similar to a traditional sporting goods store. Through simulation of activity, students made real-world decisions that tested their intuition, knowledge, and familiarized them with inventory concepts in an active setting. Through assessment, it was determined that the exercise was successful. An important note is that simulations must be well planned and can be expensive to operate.

In today's learning environment, computer-supported collaborative learning is critical to successful student engagement. If designed properly, computer software can serve as a tool to bring any subject to life. According to Ada (2008), the computer fosters social creativity by bringing students together for a common goal. Ada's 2008 study utilized activity theory to assess social creativity by means of computer-supported collaboration. The results confirmed a positive relationship between a well-designed computer activity and the willingness for students to engage willingly. As with other tools, computer-supported collaborative learning can be a valuable pedagogical activity if designed properly and leadership is applied.

There are several other methodologies that can be utilized to engage students beyond the traditional application. Universities have utilized guest speakers for years. However, to help students to want to engage, a planned trip to a corporation or factory will stimulate student interest. This is especially true if the professor is well-prepared to bring the textbook to life during the visit. 
The traditional discussion board has been a valuable tool in the online classroom since distance learning began. Creating a discussion board with critical thinking exercises and facilitating a robust weekly discussion has much value. If taken a step further and made interactive, the discussion board can be utilized to encourage students to want to engage. This requires instructor input and probing responses to student input.

Figure 2. Academic Value Chain as modified from Sasse, C., Schwering, R., \& Dochterman, S. (2008). Rethinking faculty role in a knowledge age. Academy of Educational Leadership Journal. (12)2, 35-49.

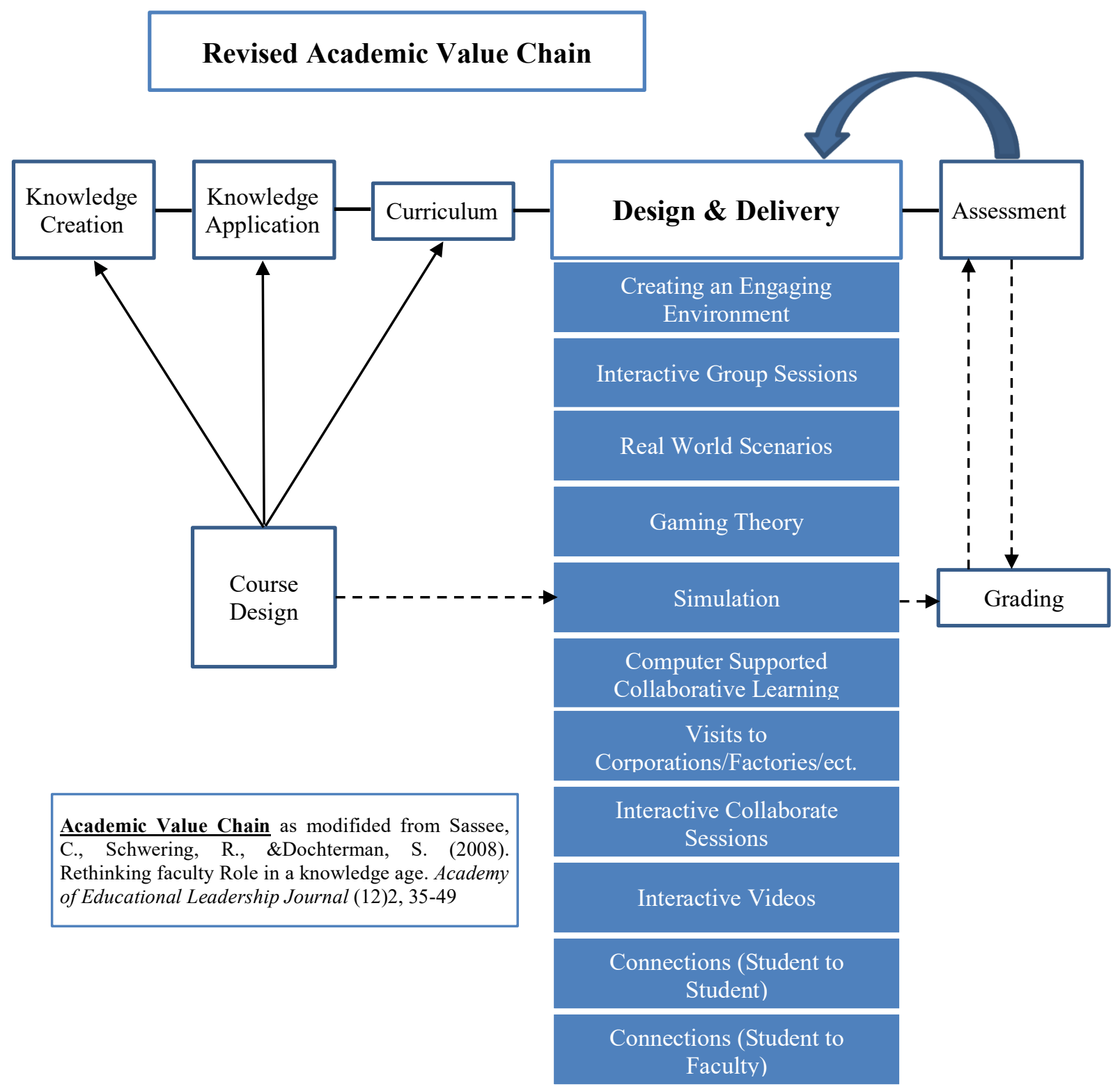

Figure X. Adapted from Sassek, Schwering \& Dochterman, 2008.

Collaborate sessions bring the professor into a traditional online course. Requiring online collaboration several times per term will make students feel part of the class and help them feel comfortable with the material. Each collaborate session should be interactive by utilizing the learning management tools available to put students in breakout sessions and encourage critical thinking to occur during the session. This same concept works for videos. Videos can 
be a valuable tool if they are used interactively. Professors can utilize videos with stop points and questions. They should ensure that the topic is relevant and that students are engaging with one another. Therefore, with the thought of engaging students in mind, figure 2 demonstrates including the faculty to focus on the design and delivery phase of the process.

As noted earlier, the value chain is a depiction of how supporting elements of the organization complement the strategic plan and bring value added to the production process. In academia, course design is the product. To ensure success, faculty must reinvent the process and emphasize the downstream focus of the course design process. Designing courses to ensure that students want to engage instead of just going through the motions will enhance the academic experience.

\section{FOCUS GROUP}

The information discussed to this point was presented to a focus group of 36 attendees at the prestigious Great Lakes Conference on Teaching and Learning at Central Michigan University in May 2017. Participants represented educators from the United States and Canada. Thirty-six conference participants volunteered to contribute to the focus groups. Participants were briefed on the background, literature review, and ideas noted in the current research. Participants were then placed in five evenly numbered groups and instructed to identify ideas they utilized in the classroom or online. Each group was facilitated by one of the authors and ideas captured for inclusion in this research. Tables below are results of efforts by the four focus groups.

Table 4. Results from Focus Group One. Created by Authors.

\begin{tabular}{l|l}
\hline \multicolumn{1}{c}{ Idea } & \multicolumn{1}{c}{ Execution } \\
\hline Social Media - Organic/student interest driven & $\begin{array}{l}\text { Structure is required to establish - Privacy rules and there } \\
\text { should be polling for interest }\end{array}$ \\
\hline Competitive grading & $\begin{array}{l}\text { Students can opt out of final if in the top tier } \\
\text { Response devices (Clickers) }\end{array}$ \\
\hline Top Hat & Obvious application if geared toward course topic. \\
\hline Practitioner career \& connections guest speakers & Real life examples / Storytelling \\
\hline Labs "hands on" & $\begin{array}{l}\text { Allow students to "fall", make mistakes - especially before } \\
\text { high stakes careers }\end{array}$ \\
\hline Safe spaces & \\
\hline Intake assessment of interest & \\
\hline
\end{tabular}

Table 5. Results from Focus Group Two. Created by Authors.

\begin{tabular}{|c|c|}
\hline \multicolumn{2}{|c|}{ Focus Group 2} \\
\hline Idea & Execution \\
\hline Use of horses & Used for a culture of leadership, empathy \\
\hline Games for examination preparation & Flash cards \\
\hline Simulations & Commercial or created by professor \\
\hline Service Learning & Sustainability \\
\hline Get out of the classroom & Traditional and online field trips \\
\hline
\end{tabular}

Table 6. Results from Focus Group Three. Created by Authors.

\begin{tabular}{|c|c|}
\hline \multicolumn{2}{|c|}{ Focus Group 3} \\
\hline Idea & Execution \\
\hline Mystery Shopper Concept & Check out the competition \\
\hline Experiential Activities & Built around learning outcomes \\
\hline Association of Experiential Education & Support \& ideas \\
\hline Read \& take test & Small percentage of students do not want to engage \\
\hline Utilize learning styles of students & Standardized testing early in class \\
\hline
\end{tabular}


Table 6. Results from Focus Group Four. Created by Authors.

\begin{tabular}{l|l}
\hline \multicolumn{1}{c}{ Idea } & \multicolumn{1}{c}{ Focus Group 4 } \\
\hline Student to Student peer learning & $\begin{array}{l}\text { Online or face-to-face, assign students to take the lead in } \\
\text { various discussions, as a teaching assistant }\end{array}$ \\
\hline Students as subject-matter-experts & $\begin{array}{l}\text { Identify students with specific experiences in topic areas and } \\
\text { assign them as focus group leaders }\end{array}$ \\
\hline Learning community of practice & $\begin{array}{l}\text { Pre-class assignment -Allow students to self-select to study } \\
\text { from subject areas chosen by instructor. Students "deep dive" } \\
\text { into subject together. }\end{array}$ \\
\hline
\end{tabular}

Table 7. Results from Focus Group Five. Created by Authors.

\begin{tabular}{l|l}
\hline \multicolumn{1}{c}{ Idea } & \multicolumn{1}{c}{ Focus Group 5 } \\
\hline Mobile Apps & Open meeting, Yammer (CMU Website), Facebook \\
\hline E-Portfolios & Create a record of success \\
\hline Traditional Games & Scavenger hunt \\
\hline At home science experiment & With selfies \& descripters \\
\hline Choose your own adventure & Integrated writing, different perspectives \\
\hline Telephone game & Writing example \\
\hline Walk around & Case Studies \\
\hline
\end{tabular}

Enthusiasm displayed by the focus groups indicated a high level of interest in connecting students in a manner that makes them want to engage. A point of note is despite plenty of options, this session was one of the most attended sessions at the conference. Feedback was extremely positive and each group generated several valid exercises to use in the traditional or online classroom as evidenced above.

\section{CONCLUSION}

The bottom line is that any classroom exercise can be engaging, if the instructor is willing to and actively attempts to motivate the students. Courses should be designed with a goal of making interactive students want to engage. Table 3 discusses open-ended questions and lectures. Remember that "talking is not teaching." While the traditional lecture will never disappear, it should be limited and supplemented with meaningful activities. There are options for every budget and students deserve the best. They are voting with their feet; it is our responsibility to make the learning environment meaningful so that gainful employment is the result.

\section{AUTHORS' NOTE}

All rights reserved. No part of this research may be used or reproduced by any means, graphic, electronic, or mechanical, including photocopying, recording, taping or by any information storage retrieval system without the written permission of the author except in the case of brief quotations embodied in critical articles and reviews.

\section{AUTHOR BIOGRAPHIES}

All authors are members of the Faculty Partner Team at Central Michigan University.

\section{REFERENCES}

Ada, W. (2008). Computer supported collaborative learning and social creativity: A case study of fashion design. Journal of Information, Information Technology, and Organizations, 3(1), 17-39.

Barnett, B. (1992). Teaching and research are inescapably incompatible. Hronicle of Higher Education, p.A40.

Brown, P., Roediger, H., \& Mcdaniel M. (2014). Make it Stick: The Science of Successful Learning. The Belnap Press of Harvard University Press. Cambridge Massachusetts, London England.

Chiong, R., Jovanovic. J. (2012). Collaborative Learning in Online Study Groups: An evolutionary game theory perspective. Journal of Information Technology Education, 11(1), 82-101. 
Ellis, A. (2001). Student-centered collaborative learning via face-to-face and asynchronous online communication: What's the difference? In Proceedings of the $18^{\text {th }}$ Annual Conference of the Australian Society for Computers in Learning in Tertiary Education. Melbourne Australia, 169-177.

Finegold, A. \& Cooke, L. (2006). Exploring the attitudes, experiences, and dynamics of interaction in online groups. The Internet and Higher Education, 9(3), 2001-2015.

Gabriel, M. (2004). Learning together: Exploring group interactions online. Journal of Distance Education, 10(3), 54-72.

Klassen, K., \& Willoughby, K. (2003). In-class simulation games: Assessing student learning. Journal of Information Technology Education, 2.

Meister, J. \& Willyerd, K. (2010). The 2010 workplace: How innovative companies attract, develop, and keep tommorow's employees today. New York: Harper Collins Publishers.

Meyer, K. A., \& McNeal, L. (2011). How Online Faculty Improve Student Learning Productivity. Journal of Asynchronous Learning Networks, 15(3), 37-53.

Roland George Investment Program (February 21, 2017). Stetson University. Retrieved from: http://www.stetson.edu/business/roland-george/

Sasse, C., Schwering, R., \& Dochterman, S. (2008). Rethinking faculty role in a knowledge age. Academy of Educational Leadership Journal. 12(2), 35-49.

Undergraduate degree earners report (2016). National Student Clearinghouse Report. https://nscresearchcenter.org/wpcontent/uploads/2014-15UndergradDegreeEarnersRpt.pdf

Wilmore, T. (2014). Game Camp. How to "gamify" your classes. In Proceedings for the 2014 Great Lakes Conference on Teaching and Learning. Mt. Pleasant Michigan: Central Michigan University. 
NOTES 